\title{
Force-displacement relationship of the butterfly-shaped beams based on gene expression programming
}

\author{
Alireza Farzampour ${ }^{1}$, Iman Mansouri ${ }^{2}$, Seyed Javad Mortazavi ${ }^{3}$, Jong Wan Hu 4,5, * \\ ${ }^{1}$ Department of Civil and Environmental Engineering, Virginia Tech, Blacksburg, United States \\ ${ }^{2}$ Department of Civil Engineering, Birjand University of Technology, Birjand, Iran \\ ${ }^{3}$ Department of Civil Engineering, Shahid Bahonar University of Kerman, Kerman, Iran \\ ${ }^{4}$ Department of Civil and Environmental Engineering, Incheon National University, Incheon \\ 22012, South Korea \\ ${ }^{5}$ Incheon Disaster Prevention Research Center, Incheon National University, Incheon 22012, \\ South Korea \\ * (Corresponding author, E-mail: jongp24@inu.ac.kr)
}

\begin{abstract}
Structural steel plates with engineered cut-outs to exhibit controlled yielding mechanism is recently proposed for desirable structural performance compared to conventional systems. Butterfly-shaped beams with hexagonal cut-outs inside of the beam's web is implemented to better align the bending strength diagram along the link length with the corresponding demand shape of the applied moment diagram. In previous studies, it has been reported that these links have a substantial energy dissipation capability and sufficient ductility which necessities further investigations and structural behavior prediction studies. In this study, a set of 240 nonlinear finite element models are developed for creation of a database and subsequently calibrated with finite element software packages. The capability of the gene expression programming (GEP) is explored for prediction of force-displacement relationship of a butterfly-shaped beam. Two new models are developed based on the reliable generated database. Subsequently, the proposed models are
\end{abstract}


validated with several conducted analysis and statistical parameters, for which the comparisons are shown in details. The results represent that the proposed models are able to predict the forcedisplacement relationship of a butterfly-shaped beam with satisfactory accuracy.

Keywords: Structural fuses, Butterfly-shaped beam, Finite element analysis, Gene expression programming.

\section{Introduction}

Under severe earthquakes, the ductile behavior of the structural elements allows inelastic drifts

leading to the overall system's energy dissipation capability (Farzampour and Eatherton 2018b; Luth et al. 2008; Mansouri et al. 2016b; Mirzai et al. 2018, 2019; Mirzai and Hu 2019; Saffari et al. 2013, Farzampour and Yekrangnia 2014). In various structural applications, shear links could be implemented by strategic material removal to concentrate the inelasticity and damages in one part of the structure while the remaining parts are intact and undamaged (Atasever et al. 2018; Farzampour and Eatherton 2018a; Kim et al. 2016; Zeynali et al. 2018, Farzampour et al. 2018). Along the same lines, a promising type of a structural fuse for use in different structural applications is butterfly-shaped beams in which the steel web plate have cutouts inside leaving butterfly-shaped links for better aligning the capacity diagram with corresponding demand diagram (Lim and Kim 2017; Castaldo et al. 2016). Figure 1 shows the implementation and details of the butterfly-shaped beam in different structural applications.

Previous studies indicated that using butterfly-shaped shear links within the structures leads to reduction in inelasticity concentration at the critical areas (Farzampour and Eatherton 2018a; 2018b; Farzampour and Eatherton 2019, Farzampour et al. 2019). This concept could be 
implemented for designing various high-rise and low-rise buildings as well as the fortification of the existing structures. Butterfly-shaped dampers are studied previously (Farzampour and Eatherton 2019) for beam-column connection protection from significant damages under earthquakes. These new dampers are able to concentrate the plastic deformations in structural shear links while the columns and beams remain almost elastic. In addition, several studies showed that these fuses are able to undergo $30 \%$ shear angle ratios if the possibility of the buckling is prevented (Farzampour and Eatherton 2017; Tsai et al. 1993). Figure 1b shows a typical butterfly-shaped shear link, and the general loading condition and geometrical properties, and the moment demand versus moment capacity of these links.

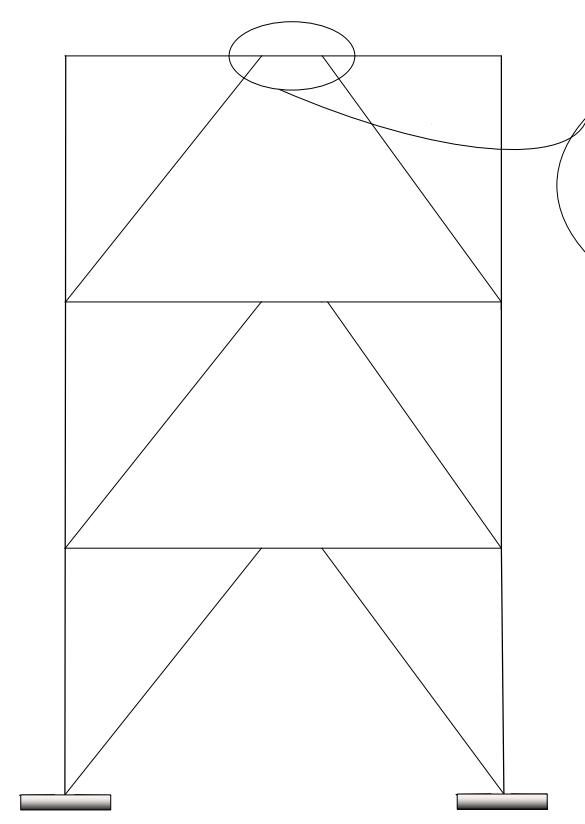

a) Eccentrically Braced Frame Application

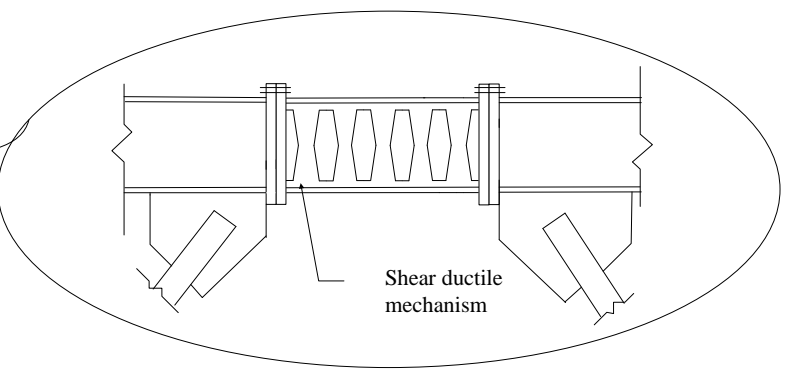

b) Butterfly-shaped fuse

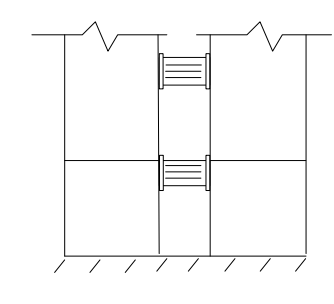

c) Coupled shear wall Application

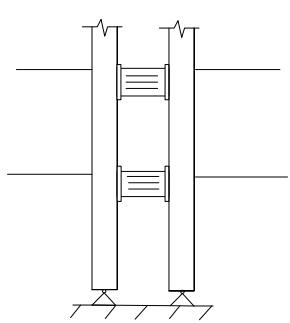

d) Linked Column

a) Examples of the implementation of a buttrefly-shaped fuse ( Farzmapour and Eathertn 

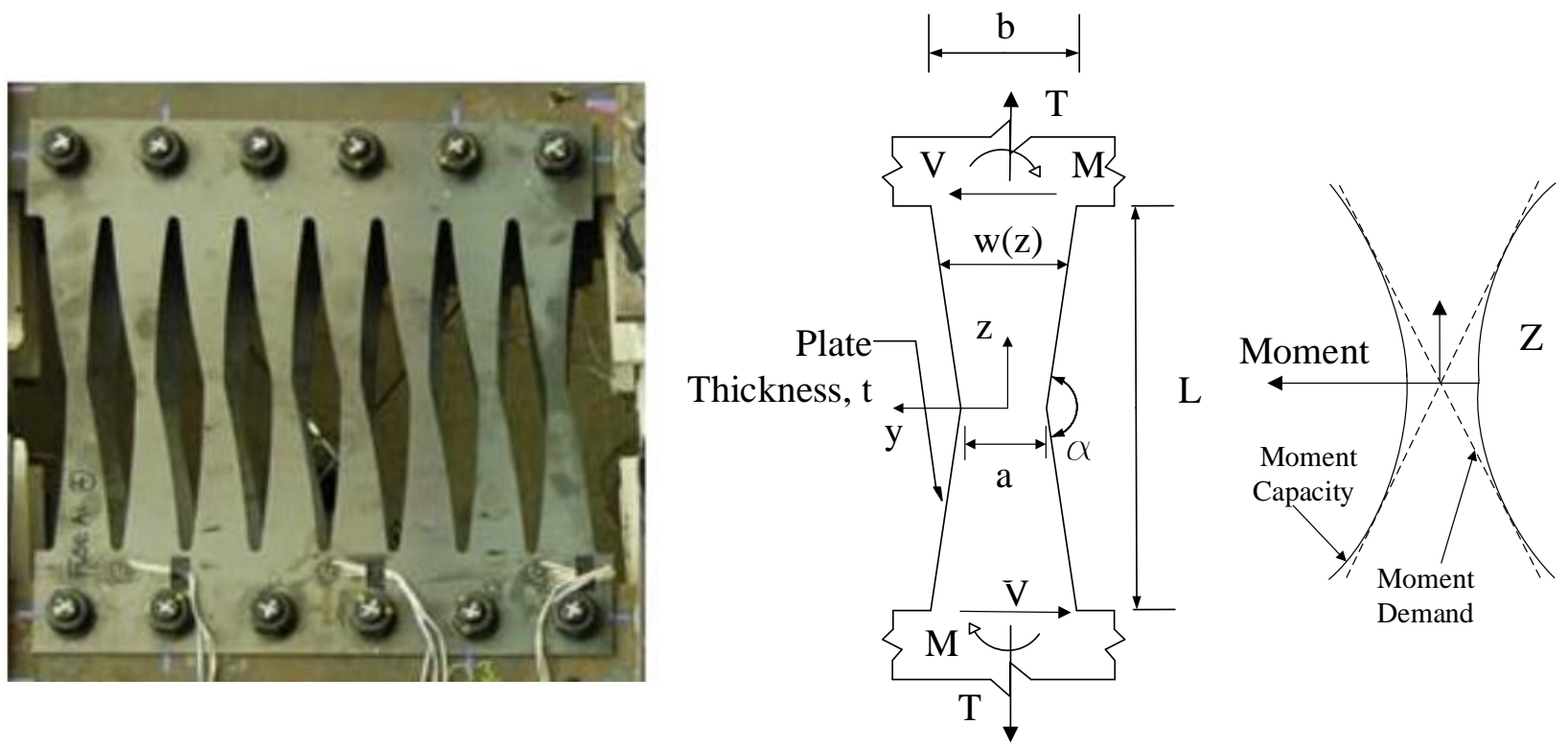

b) The gemoetrical shapes, and the laoding condition of a typical buttrefly-shaped link

Figure 1. The detailed information of a butterfluy-shaped link and applciations

Along the same lines, different studies showed that straight shear links and butterfly-shaped shear links are capable of controlling structural response of multistory buildings under earthquakes, and then be accessible for replacement purposes (Farzampour and Eatherton 2019; Farzampour et al. 2019). These links represent high ductility and stiffness; however, they are subject to brittle limit states, especially buckling (Farzampour 2019). The structural shear links employed in various applications could act as structural fuses since they are able to yield and limit the demand force on the surrounding structural elements. For addressing various limit state issues, the effect of various geometrical properties are studied previously to indicate appropriate design ranges for specific applications (Farzampour and Eatherton 2018b). It is shown that compared to other types of links, the butterfly-shaped links are capable of having hinges far from the sharper areas, full hysteric behavior, significant buckling resistance, and applicable for space-constrained areas. 
Hysteretic dampers such as the added damping and stiffness (ADAS) and triangular-plate added damping and stiffness device (TADAS) have tapered fuses bent about their minor axis (Whittaker et al. 1991, Tsai et al. 1993). Similarly, tapered fuses can be bent about their major axis (in-plane bending) to create larger stiffness. In-plane implementation of the fuses has been shown to have substantial energy dissipation capability, ductility, and large distribution of yielding. To control the drift response of mid-rise buildings in-plane fuses have been implemented with similar shapes compared to butterfly-shaped fuses for the purposes of desirable energy dissipation and reducing the demands on the framing members ( $\mathrm{Li}$ and $\mathrm{Li}, 2010)$.

In recent years Gene expression programming (GEP) has been for many engineering problems (Ebrahimzade et al. 2018; Gandomi and Alavi 2012; Gandomi et al. 2014b; Güllü 2012; Mahdavi Jafari and Khayati 2018; Mansouri et al. 2016a). This method is implemented in this study to investigate the structural prediction of butterfly-shaped beams' behavior. This new data-driven method uses individual population to extract the best solution according to one or several gene operations (Mansouri et al. 2017a). It is noted that the tangible discrepancy in previously employed method of Genetic Programming (GP) and GEP is related to the nature of the used programs. The GP considers parse tree programs length, while in GEP, the programs are in the format of linear strings with fixed length (Mansouri et al., 2017b), which are represented as the chromosomes. In this paper, the GEP method is employed to assess the force-displacement relationship of butterfly-shaped beams. The validated reduced-order models are developed and a database is generated using OpenSees platform. A total of 240 models are used to establish the database for further analysis related to the various geometrical properties. The results of the developed models are culminated in deriving force-displacement relationships for a typical butterfly-shaped beam with general geometrical properties. 


\section{Gene expression programming}

As a progressive algorithm, gene expression programming (GEP) is competent of determining functions from the vast datasets via computer programs evolvement that adopt the role of a living organism. It is generally accepted that they are able to ascertain the links among variables and adapt them by varying their shapes and sizes (Bingöl and Kılıçgedik 2018; Mansosuri and Farzampour 2018).

By using genetic operators, population evolution occurs upon the selection of a population consisting of individuals (Gandomi et al. 2014a). The algorithm, shown in Figure 2, is terminated if an acceptable fitness level is achieved. A comparison of the predicted and actual values distinguishes minimal errors and such procedure is repeated until a satisfactory solution is obtained (Nie et al. 2013). There are two GEP components; chromosomes and expression trees (ETs). Chromosomes represent a mathematical expression consisting of one or more genes. The head and the tail are two main components of the genes. The tail only includes leaf nodes related to ET, and the head contain both leaf and internal nodes. In canonic GEP, the gen number and size of the head and the gene are considered as the input parameters for the algorithm. Upon transforming every chromosome into an ET, a mathematical relation is deduced. It is note that that for multiagenetic chromosomes, all ETs are connected by their root node with a linking function. The linking function is consider das the additional operator in this study for the GEP system.

Numerous parameters should be taken into account amidst the GEP optimization process. The range of varying parameters include fitness function, genetic operators and relevant rates, linking function, random numerical constant status, function set, size of genes, quantity of genes, size of 
population and learning algorithm, etc. Despite some available guidelines on optimal parameter selection, the simplest and most efficient approach is to apply a trial and error process (Onen 2014). According to previous literature, GEP generates favorable results if there is an increase in the head size. Nevertheless, a head that is too large can hinder GEP performance. Several researchers recommended a head size of 5-30 (Azamathulla 2012; Bingöl and Kılıçgedik 2018; Zakaria et al. 2010). Evidently, greater head size entails higher computation costs. Thus, a balance is required between efficiency and accuracy. In this study, initially, a single gene with five head sizes is implemented. Then, gene numbers and head sizes are increased upon every run. There were no substantial improvements by over three genes and head sizes of over eight. On the basis of prior knowledge (Azamathulla 2012), linking functions are selected for specific problems. Here, we applied subtraction, addition, division, and multiplication as linking functions. The most favorable fitness values were obtained by linking sub-expression trees (sub-ETs).

The head is responsible for encoding variables and functions in GEP. Numerous function sets may be utilized. It is noted that choosing the appropriate function is not simple and appropriate guessing is beneficial. In this study, basic arithmetic operators $(+,-, \times, /)$, various mathematical functions (natural logarithm, exponential, $x^{y}$, square root) were used in addition to various trigonometric functions (arctangent, tangent, cosine, sin). Lastly, in order to configure the chromosomes, genetic operators were required. With the increasing mutation and transposition probability, GEP performance is typically improved. The sufficient mutation probability is $0.03-0.10$. Every genetic operator was combined to achieve the genetic diversity. Table 1 lists the GEP optimized parameters. 
Table 1. Genetic parameters

\begin{tabular}{ccc}
\hline Parameter & Parameter description & Parameter setting \\
\hline P1 & Chromosomes & 100 \\
P2 & Fitness function error type & RMSE \\
P3 & Number of the genes & 3 \\
P4 & Head size & 20 \\
P5 & Linking function & Multiplication \\
P6 & Function set &,,$+- \times, /$, Pow, Sqrt, Exp, Ln \\
P7 & Mutation rate & 0.00138 \\
P8 & One-point recombination & 0.00277 \\
P9 & Two-point recombination & 0.00277 \\
P10 & Inversion rate & 0.00546 \\
P11 & Transposition rate & 0.00546 \\
\hline
\end{tabular}

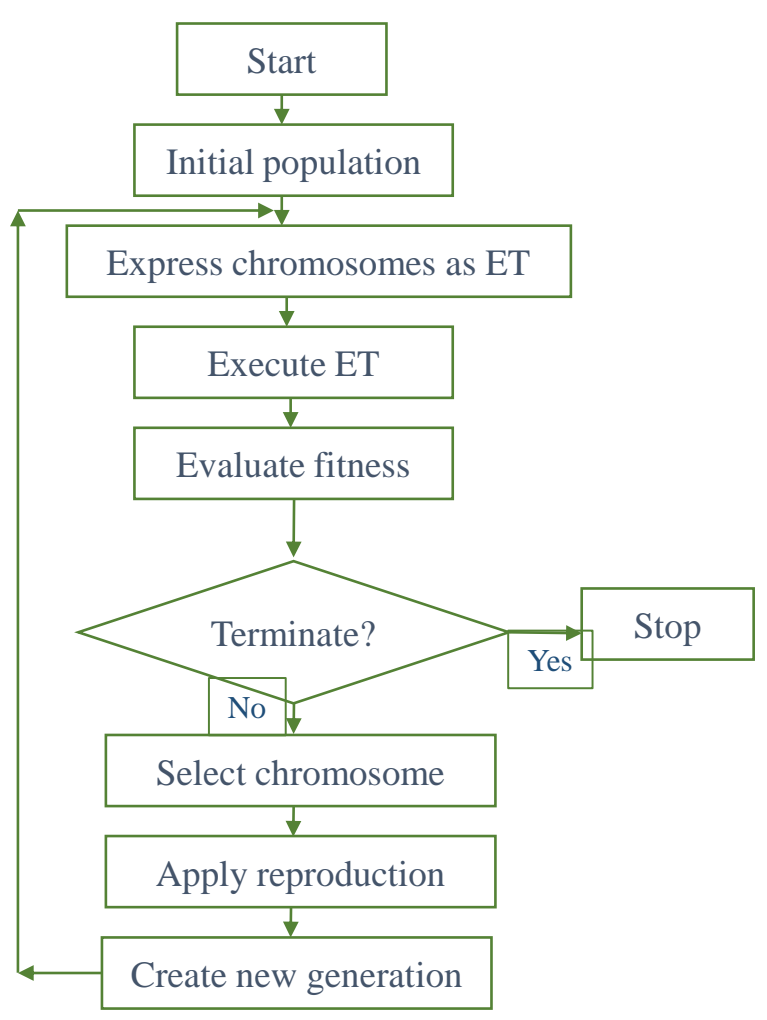

Figure 2. The gene expression programming (GEP) algorithm 


\section{Data preparation and reduced order model establishment}

The models are developed according to a comprehensive database obtained from the finite element analysis (FEA) (OpenSees software). The 240 models are generated subjected to the cyclic analysis for modeling purposes to establish a general database, based on which the forcedisplacement equations are derived accordingly. Table 2 shows the parameters of interest and associated ranges.

Table 2. The value parameters considered for establishing the GEP database

\begin{tabular}{cccc}
\hline $\boldsymbol{a} / \boldsymbol{b}$ & $\boldsymbol{b} / \boldsymbol{L}$ & $\boldsymbol{L} / \boldsymbol{t}$ & $\left.\boldsymbol{f}_{\boldsymbol{y}}, \mathbf{k s i} \mathbf{( M P a}\right)$ \\
\hline 0.1 & 0.1 & 10 & $39(269)$ \\
0.33 & 0.3 & 20 & $52(358)$ \\
0.75 & 0.5 & 40 & \\
1.0 & 0.7 & 60 & \\
& 0.9 & 80 & \\
& & 100 & \\
\hline
\end{tabular}

To ensure a successful comparison, verification studies are conducted initially. The first verification study is related to a beam with hourglass-shaped links. FE ABAQUS package is used to model the general fuse system and obtain the cyclic pushover hysteretic results. Twenty-nodded solid element with reduced integration capability is used as the selected element type to reduce the chance of shear locking and hour-glassing effects (Shin et al. 2017). A bilinear material properties with yielding strength of $379 \mathrm{MPa}$ and elastic modulus of $200 \mathrm{GPa}$ and strain-hardening of 1.38 $\mathrm{GPa}$ is considered. According to the geometry of the test, the story shear should be evaluated as the 1.42 times beam shear obtained from FEA, and the story drifts should be estimated by the beam chord rotation divided by 1.34 . The beam chord rotation is defined as the transverse displacement by the beam's clear span length. Figure 3 compares shear-story drifts responses with the 
corresponding laboratory test of the beam with hourglass-shaped links. In addition, it is reported that that the buckling limit state is occurred at the $2 \%$ drift ratio, which is precisely captured from the FE models. From the FE model, the beam strength before and after buckling were 16.46 Kips $(73.2 \mathrm{kN})$ and $11.85 \mathrm{Kips}(52.7 \mathrm{kN})$. The reported strength from the laboratory test specimen before and after buckling were 17.1 Kips $(76 \mathrm{KN})$ and $12.9 \mathrm{Kips}(57.4 \mathrm{kN})$, which shows that the FE modeling methodology was able to capture the actual behavior and limit states of the beam with shear links inside within less than $5 \%$ difference.

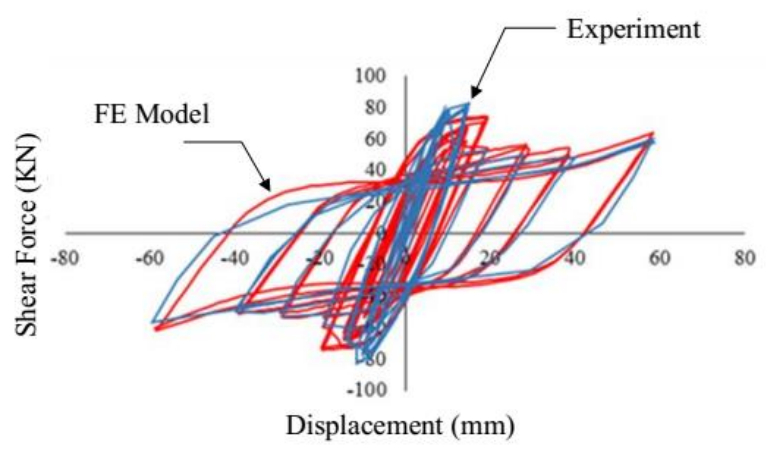

a) Load vs. deformation

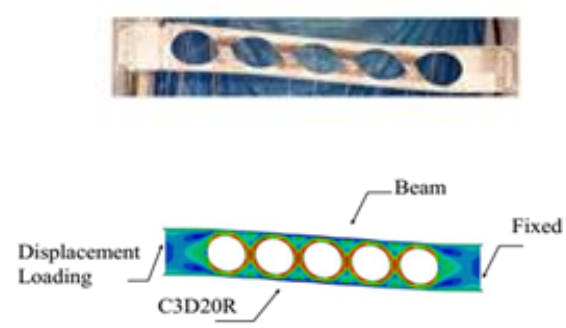

b) Test specimen and FE model

Figure 3. Verification of the finite element modeling methodology against laboratory specimens

In the second verification study, the reduced order model from OpenSees is verified with FE package results. The modeling methodology with OpenSees is conducted through validating the cyclic behavior against the FE model. A butterfly-shaped beam is modeled based on the conventional EBF system IBC (2012), and redesigned with a set of a flexural dominated links and a total length of $120 \mathrm{~cm}$ following previous studies (Frazmapour, 2019). The geometrical properties of the model is shown in Figure 4, the material model is based on the yielding stress of $36 \mathrm{ksi}$ (250 $\mathrm{MPa})$, modulus of elasticity of $29000 \mathrm{ksi}(2.0 \mathrm{E}+5 \mathrm{MPa})$ and the strain-hardening ratio of 0.0005 . 
For verifying the reduced-order model with FE model, a cyclic load previously proposed by AISC (AISC 341-16) for EBF behavior investigations is applied at one end of the shown beam in Figure 4, while the other end was fixed. This loading protocol is chosen due to having similarity in behavior of the EBF system with the studied butterfly-shaped beam. The studied FE model is shown in Figure 4.a and Figure 4.b, and the corresponding reduced-order model is shown in Figure 5.a, and Figure 5.b, respectively.

Figure 5.a shows the schematic illustration of the Opensees reduced order model. For this model the beams are modeled with elementelastic elements, since the contribution of the upper and lower plates to the inelastic total inelastic behavior is negligible. The butterfly-shaped links are modeled with displacement based beam element (dispBeamColumn) with distributed plasticity and 5 integration points. The length of the beam is equal to $120 \mathrm{~cm}$, and height of the beam is equal to $40 \mathrm{~cm}$. The links are modeled with taper shaped varying width shown in Figure 5.a, and the boundary condition for nodes are pinned which is schematically determined in Figure 5.a. The material model is Giuffré-Menegotto-Pinto Model with Isotropic Strain Hardening (Steel02 in Opensees) with yielding point of $36 \mathrm{Ksi}$ (248 MPa), modulus of elasticity of $29000 \mathrm{Ksi}$ (2e5 MPa) and the strain-hardening ratio is 0.0005 (CR1, CR2, a1, a2, a3, a4, and sigInt are 0.925, 0.15, 0.005, $1.0,0.005,1.0$ and 0 respectively).

In addition, the applied cyclic loading protocol is shown in Figure 5c. For verifying the reducedorder models with FEA. The hysteretic results of the reduced-order model verification study shows that the reduced-order model is able to capture the cyclic behavior of a typical butterfly-shaped beam with more than $98 \%$ accuracy, which is confirmed with Figure 5.b. 


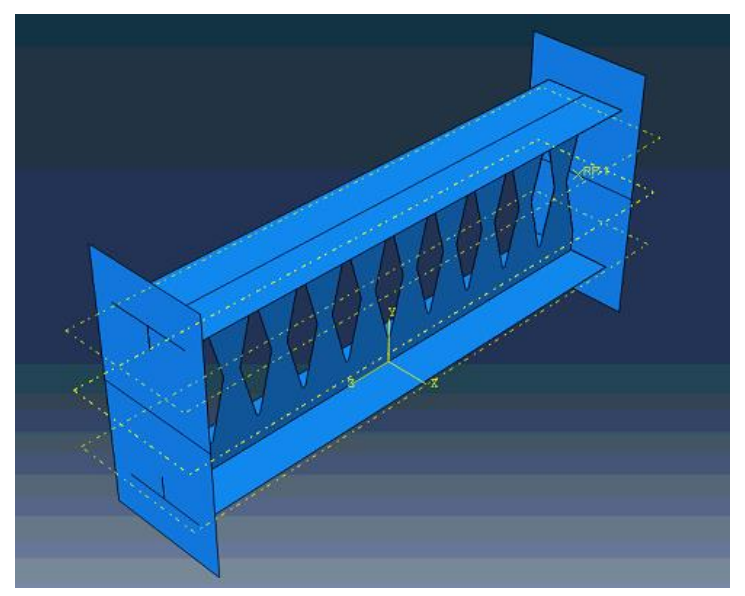

a) The model simulated in FE program

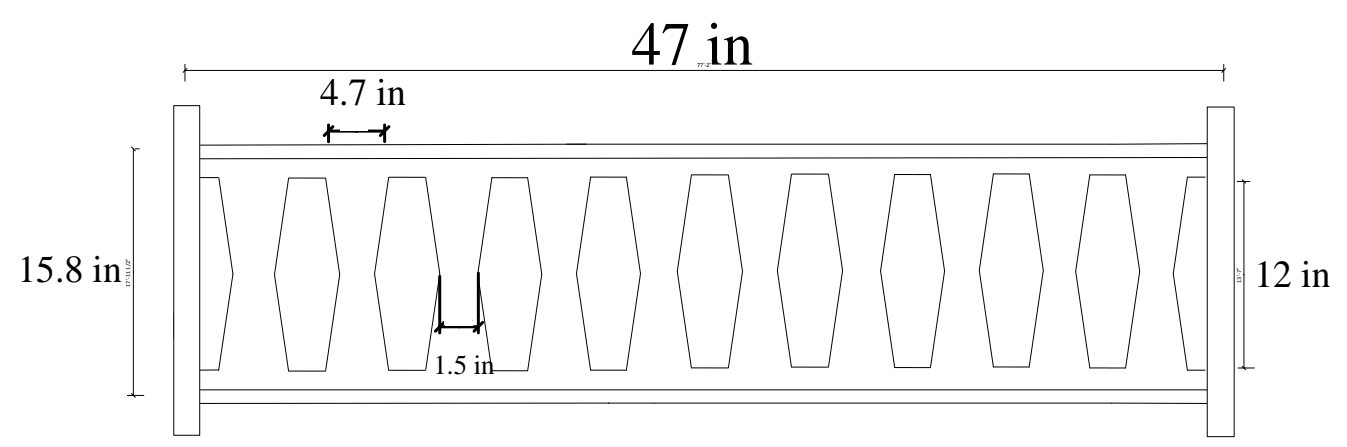

b) Details of the simulated model in FE program

Figure 4. The schematic representation of the butterfly-shaped beam model 


\section{Multi-point constraint in directions 1 and 2}

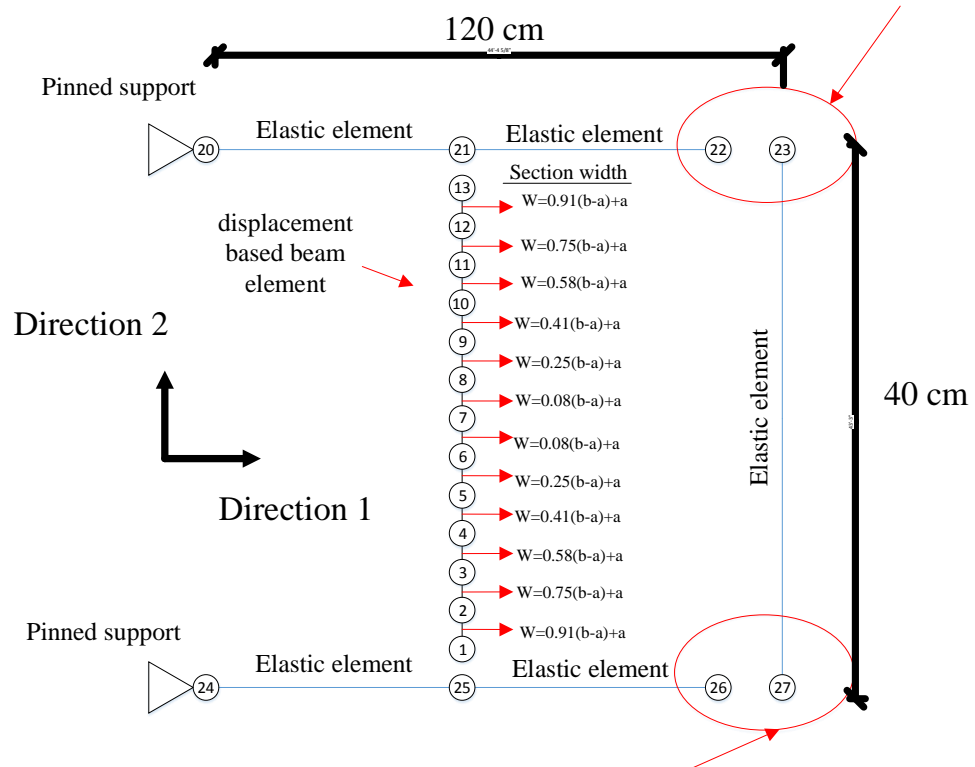

Multi-point constraint

in directions 1 and 2

a) The schematic representation of the FBF model in OpenSees

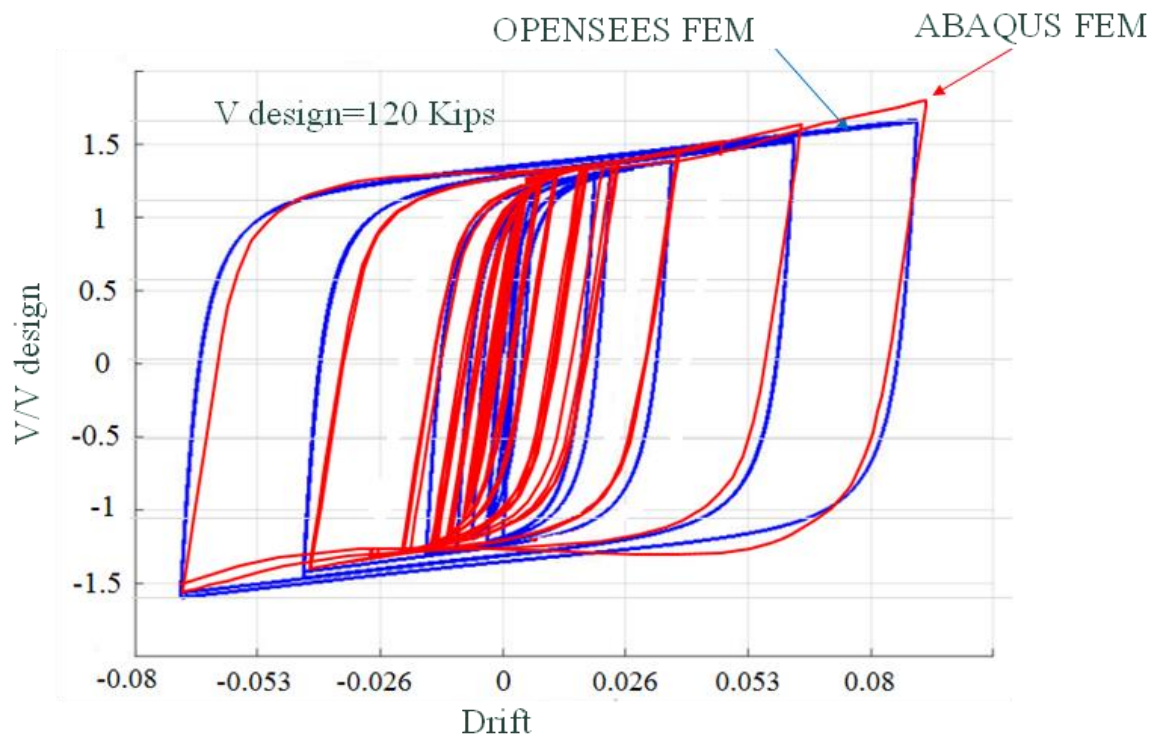

b) The verification of the reduced order model in OpenSees with FEA model (120 kips is equal to $530 \mathrm{kN})$ 


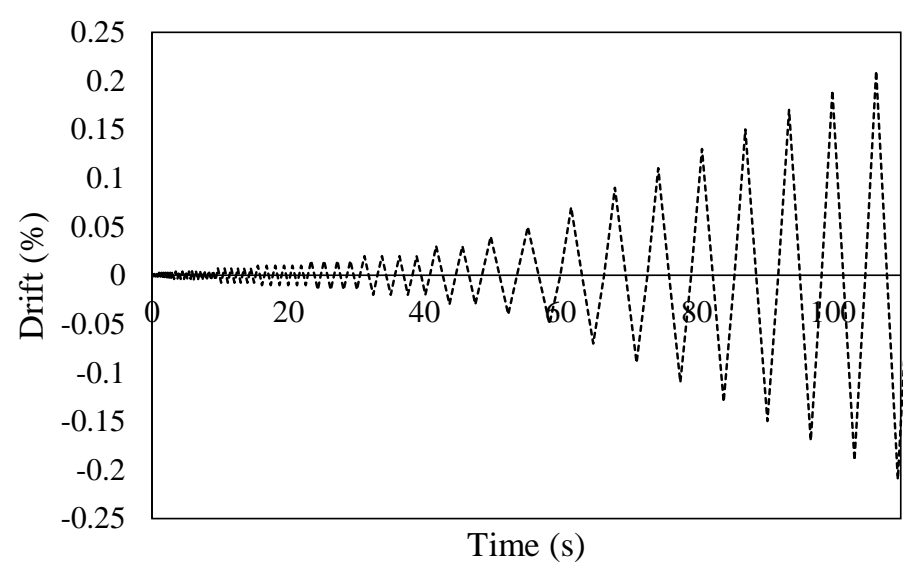

c) Loading protocol

Figure 5. The verification of the reduced-order beam model

\section{Model development}

The main purpose of this section is to propose a prediction equation for the force-deformation of butterfly-shaped beam that envelopes the hysteretic behavior subjected to cyclic loading. Figure 6. shows a cyclic envelope, which is specified by connecting the peak force responses at each displacement level. For each one of the 240 models, the envelope curve is derived and stored. The envelope curve subsequently are used for soft computational investigations and the forcedisplacement prediction equation in the next steps. 


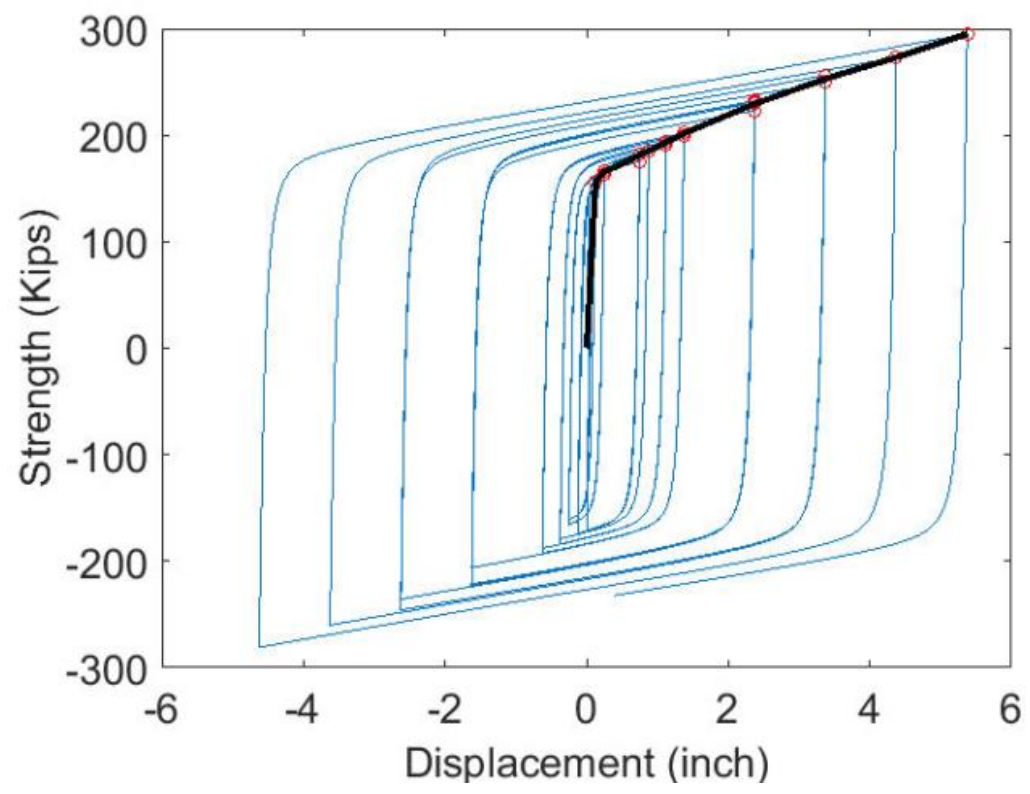

Figure 6. Example of a cyclic envelope based on hysteretic response

The considered parameters employed as the predictor variables are $a / b, b / L, L / t, f_{y}$ and $d$ in which the terms $a / b, b / L$ and $L / t$ are the geometrical ratios calculated based on the Figure $1, f_{\mathrm{y}}$ is the yielding stress in ksi, and $d$ is the vertical displacement of linking beam in inches. As a result, formulation of the shear force is formed as follows:

$$
V=f\left(a / b, b / L, L / t, f_{y} \text { and } d\right)
$$

in which $V$ (pound) is shear force of the butterfly-shaped beam. Here are two proposed prediction models:

$$
\begin{gathered}
V_{I}=\ln \left(\left(f_{y} \frac{a}{b}\right)^{(b / L) /(L / t)}\right) \times\left(100 f_{y}-f_{y}^{2(1.088-d)}\right) \\
V_{I I}=v_{1} v_{2} v_{3}
\end{gathered}
$$

in which: 


$$
\begin{aligned}
& v_{1}=(d+8.06)\left(f_{y}-\frac{L / t}{\frac{-3638.88 d+L / t}{-0.99+f_{y}+(L / t)^{d}}-\frac{d f_{y}^{b / L}}{b / L+d}}\right) \\
& v_{2}=(b / l)\left(\begin{array}{l}
\left.b / l-\frac{\left(43.47 a / b+f_{y}\right)\left(f_{y} b / L\right)\left(\sqrt{L / t}+6.02 f_{y}\right)}{\left(597137.17-\frac{35573.57}{a / b}\right)(\ln (L / t)+5.08+b / L}\right) \\
v_{3}=\frac{(a / b-8.05) \sqrt{a / b}(11.34-a / b)+0.032^{(d-0.736)}+d}{6.94-\sqrt{f_{y}}-L / t}
\end{array}\right)
\end{aligned}
$$

in which, the Eq. (2) is simple and less precise force-displacement predicting equation, while Eq. (3) is more accurate and complex. In the next section, the accuracy of the proposed equations are evaluated and studied in details.

\section{Results and discussions}

Several phases are conducted to select the appropriate model with high accuracy. Smith (1986) showed that models with the $R^{2}$ correlation coefficient of 0.64 or more, have a strong correlation between the observed and predicted values, meaning that the models' prediction capability is satisfactory. However, the insensitiveness of the model evaluation capability corresponding to the additive differences is neglected if only $R$-values are considered. For addressing this issue, the root mean square error (RSME) and the mean absolute error (MAE) are employed to have more sensitivity to discrepancies between the observed and predicted values. The RSME equation is shown in Eq. (4), which considers the summation of the error magnitudes in predictions. Along the same line, MAE equation shown in Eq. (5) indicates how large error values are expected, compared to the predicted values in average. It is clear that the model's performance would be more desirable if lower RSME and MAE values are achieved. 


$$
\begin{aligned}
R M S E & =\sqrt{\frac{1}{N} \sum_{i=1}^{N}\left(X o_{i}-X e_{i}\right)^{2}} \\
M A E & =\frac{1}{N} \sum_{i=1}^{N}\left|X o_{i}-X e_{i}\right|
\end{aligned}
$$

where $N, X o_{i}$ and $X e_{i}$ are the number of samples, observed and estimated values, respectively.

Figure 7 shows the scatter plot of the target (generated database) and predicted models (GEP). To visualize the correlation between possible variable pair consisting input variables, model and achieved variables, the scatter plots are implemented. Figure 7 shows that the testing and training datasets in which the Target is the force values obtained from OpenSees, and model means predicted force values from GEP.

To adjust the weights on the GEP, training set is used to minimize the overfitting. It is shown that if the accuracy over the training data set increases, and the accuracy of validation data set stays the same or decreases, then the overfitting would occur. In addition, to confirm the actual predictive power of the model, the testing data set is implemented. It is necessary to further decrease the data points evaluated for several different estimators, and avoid cluttering issue leading to capturing the asymptotic behavior of each respective estimator. The asymptotic behavior is captured and least squares curve-fit is calculated for each metric of each estimator with 95 percent confidence bounds. For this purpose, GEP's curve fitting is implemented to estimate the curve-fit and the confidence bounds which are shown in Figures 8-11.

It can be observed from Figure 7 that the GEP model with high $R^{2}$ values for both testing and training phases predicts the target values to an acceptable degree of accuracy. Having $\mathrm{R}^{2}$ equal to one does not show a perfect prediction and it only indicates a linear correlation between the experimental and predicted data; hence, other statistical indexes (e.g. RMSE and MAE) for 
evaluation purposes should be implemented for verifying the accuracy of predictions (Sadeghian and Fam 2015).

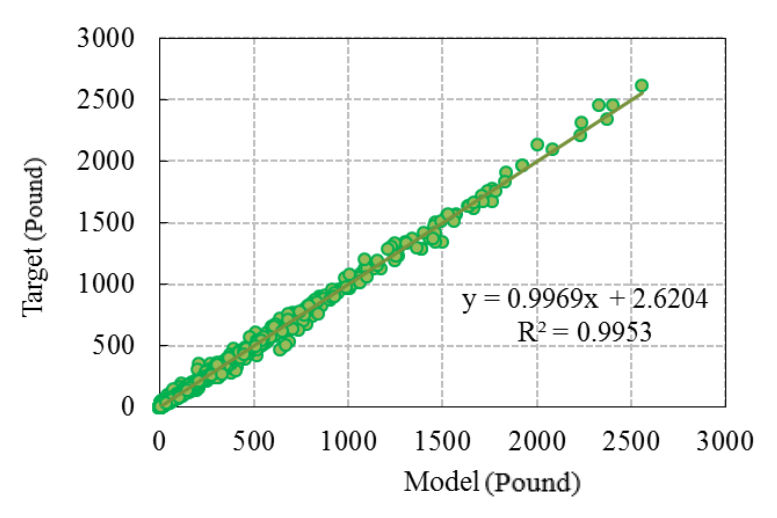

(a) Training (Pound)

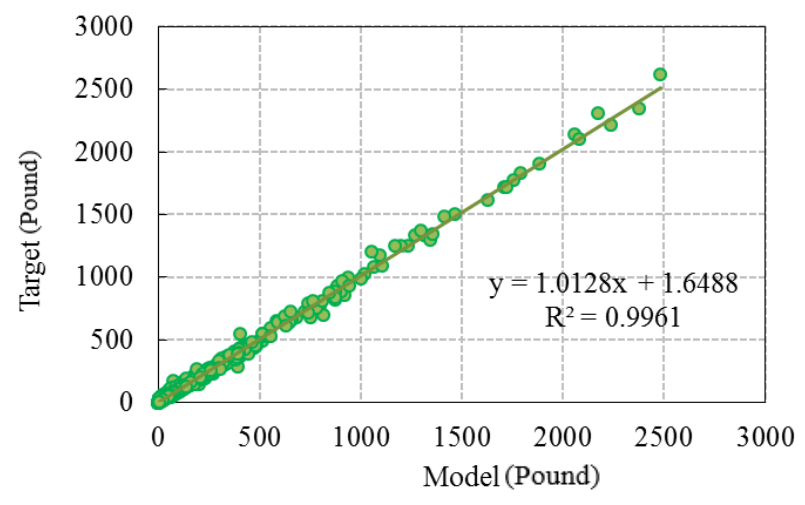

(b) Testing

Figure 7. Scatter plot of predicted values versus generated shear forces using the GEP model for Eq. 3

In addition, the curve-fitting chart shows how the models are fitting the data. For instance, Figure 8 illustrates this chart for both the training and testing phases. It is determined that the GEP based shear forces with high fitting status is able to predict the target values with an acceptable degree of accuracy; hence, the prediction equation have high accuracy in estimating the ultimate shear forces for a beam equipped with butterfly-shaped shear links. 


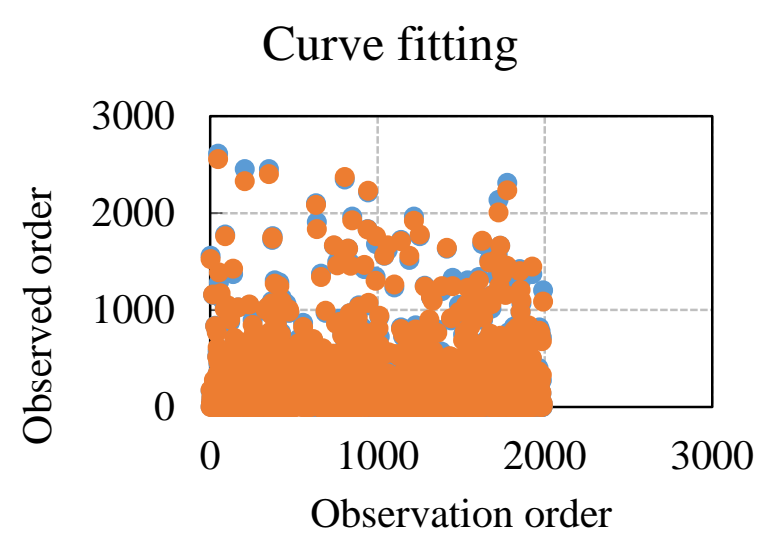

a) Curve fitted for training stage

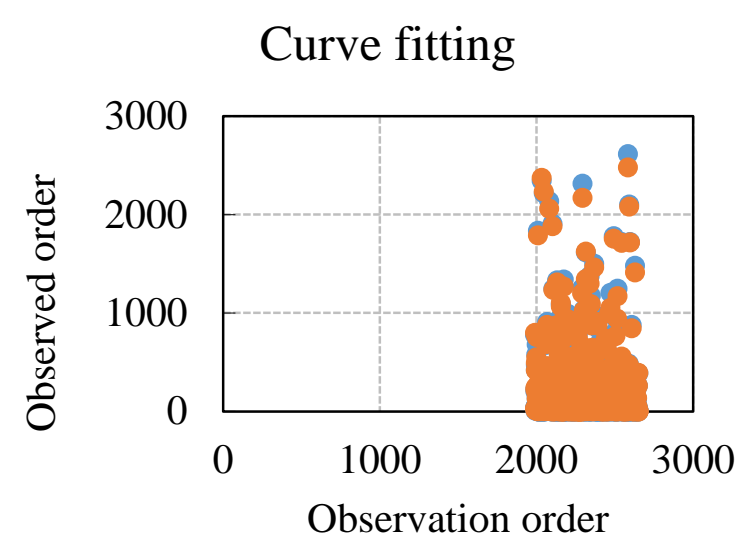

b) Curve fitted for testing stage

Figure 8. Curve fitting of predicted values versus generated shear force values using the GEP model for Eq. 3

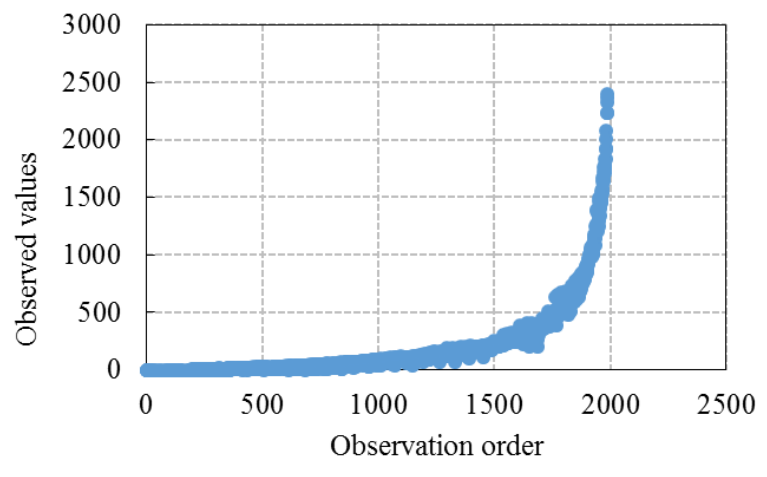

a) Target sorted fitting for training dataset

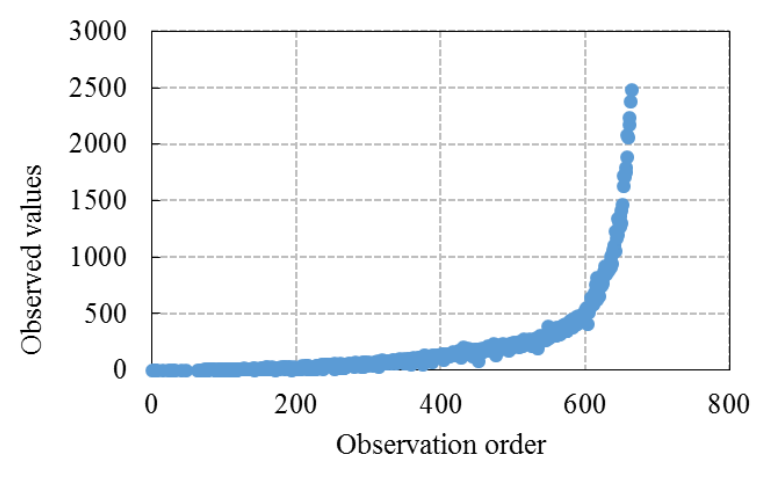

b) Target sorted fitting for testing dataset

Figure 9. Target sorted fitting of predicted values versus shear force values using the GEP model for Eq. (3)

A unique number related to each one of the possible category values are assigned in categorical variable coding. In this process, which is also called dummy variable application, the dummy values are eventually substituted with actual category designations. To indicate how the target and model output data could cover the total range, the distributions in parallel scatter plots with dummy 
random points in $\mathrm{Y}$-axis are developed and shown in Figure 10, in which dummy values versus observed values based on the proposed Eq. (3) are determined. It is concluded that the target and model outputs are well covered over the entire range of target and model outputs, and the spread, as well as overlap of the actual and predicted values are significantly close.

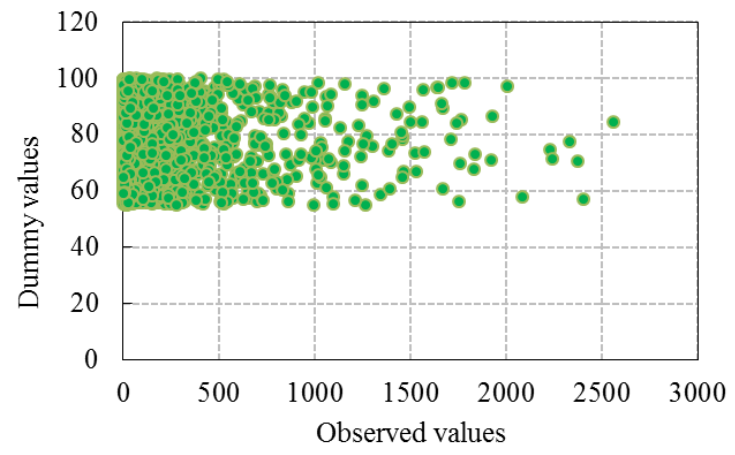

a) Model

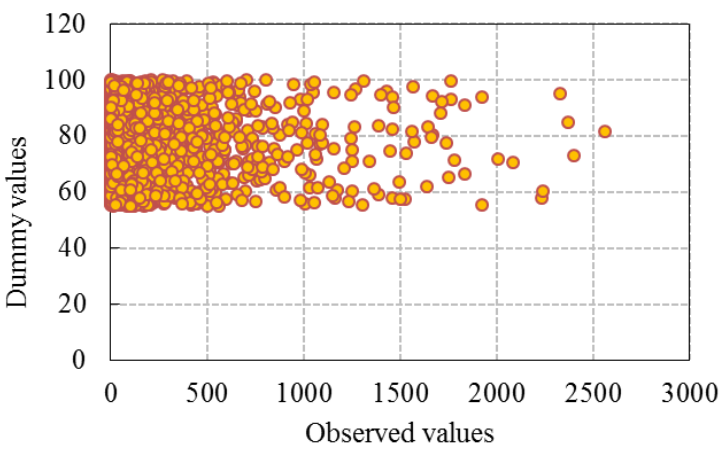

b) Target

Figure 10. Training: dummy values versus observed values related to Eq. 3

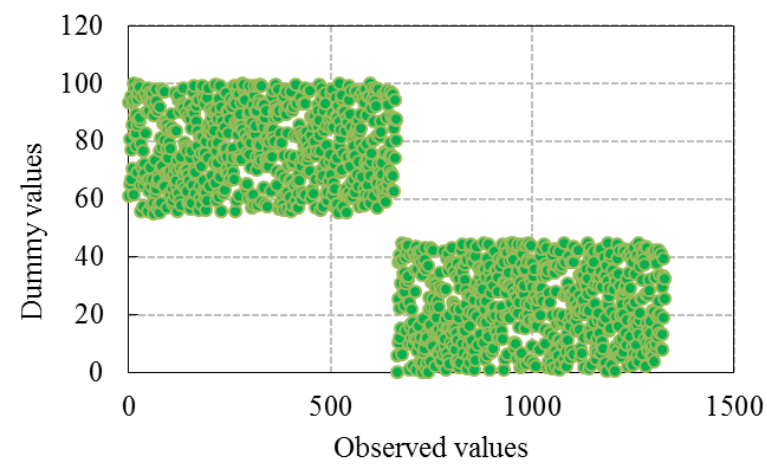

c) Model

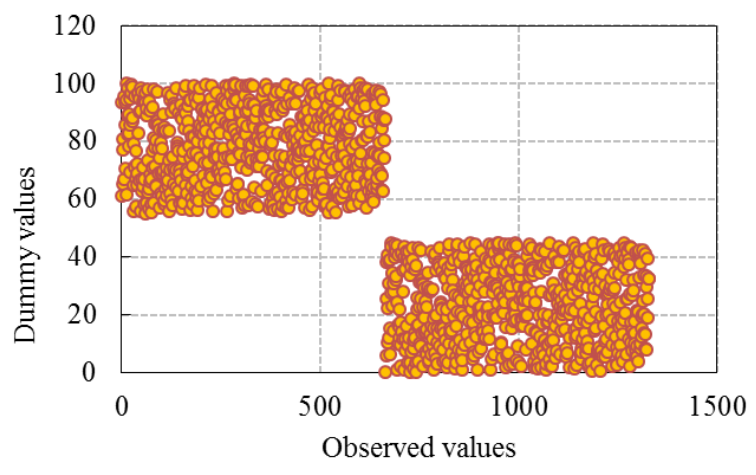

d) Target

Figure 11. Testing: dummy values versus observed values based on Eq. 3 
The proposed equations results for training and testing set are represented in Table 3 . It is concluded that based on the Table 3, the accuracy of the proposed Eq. (3) with more complicated formulization compared to Eq. (2) is high due to close to one $\mathrm{R}^{2}$ values indicating better correlation between the results. For Eq. (3) The RSME and MAE for training and testing sets are close with less than $0.5 \%$ difference. However, this difference between the testing and training statistical parameters is between $10 \%$ and $20 \%$ for the model proposed in Eq. (2). The operator is able to decide to use either of the equations based on the application and required accuracy for design purposes.

Table 3. The statistical data and accuracy of the proposed equations

\begin{tabular}{ccccccc}
\hline Model & \multicolumn{5}{c}{$\boldsymbol{V}_{\text {target }}$ vs. $\boldsymbol{V}_{\text {model }}$} \\
\hline & \multicolumn{2}{c}{$\mathrm{R}^{2}$} & \multicolumn{2}{c}{ RMSE } & \multicolumn{2}{c}{ MAE } \\
\cline { 2 - 7 } & Training & Testing & Training & Testing & Training & Testing \\
\hline I (Eq. 2) & 0.83 & 0.82 & 136.37 & 156.17 & 72.43 & 79.32 \\
II (Eq. 3) & 0.99 & 0.99 & 22.28 & 23.04 & 13.30 & 13.78 \\
\hline
\end{tabular}

\section{Conclusions}

The application of the relatively new soft computing approach of GEP to predict the forcedisplacement relationship of butterfly-shaped beams is described in this study. For this purpose, 240 finite element models were generated using OpenSees platform to establish a database. Two GEP models were developed accordingly to predict the force-displacement of butterfly-shaped beams with general geometrical properties based on the generated database. 
The results of the GEP-based models were able to accurately predict the butterfly-shaped beams shear force at any specified displacement value. The model's validity is tested for various parts beyond the training data, and it is shown that GEP prediction model satisfies the various criteria. Furthermore, the validation phase determines the model efficiency for general shear force estimation of butterfly-shaped beams. Several factors $(a / b, b / L, L / t, f y$ and $d)$ are represented within the model to consider the effect of the different geometrical and material properties of a typical butterfly-shaped beam. The accuracy of the proposed equations are shown to be high due to the close agreement in $\mathrm{R}^{2}$, RMSE, and MAE between training and testing data sets. Therefore, it is concluded that the proposed models could be implemented for design and pre-planning purposes.

\section{Acknowledgments}

This research was supported by Basic Science Research Program through the National Research Foundation of Korea (NRF) funded by the Ministry of Science, ICT \& Future Planning (2017R1A2B2010120).

\section{References}

Atasever, K., Celik, O. C. and Yuksel, E. (2018). "Development and Cyclic Behavior of U-Shaped Steel Dampers with Perforated and Nonparallel Arm Configurations." International Journal of Steel Structures, 18(5), pp. 1741-1753.

Azamathulla, H. M. (2012). "Gene expression programming for prediction of scour depth downstream of sills." Journal of Hydrology, 460-461, pp. 156-159. 
Bingöl, S. and Kılıçgedik, H. Y. (2018). "Application of gene expression programming in hot metal forming for intelligent manufacturing." Neural Computing and Applications, 30(3), pp. $937-945$.

Castaldo, P., Palazzo, B. and Perri, F. (2016). "Fem simulations of a new hysteretic damper: The dissipative column." Ingegneria Sismica, 33(1), pp. 34-45.

Ebrahimzade, H., Khayati, G. R. and Schaffie, M. (2018). "A novel predictive model for estimation of cobalt leaching from waste Li-ion batteries: Application of genetic programming for design." Journal of Environmental Chemical Engineering, 6(4), pp. 3999-4007.

Farzampour, A. and Eatherton, M. R. (2017). "Lateral torsional buckling of butterfly-shaped shear links." Proc., SSRC Annual Stability Conference Structural Stability Research Council, San Antonio, USA.

Farzampour, A. and Eatherton, M. R. (2018a). "Investigating limit states for butterfly-shaped and straight shear links." Proc., 16th European Conference on Earthquake Engineering, 16ECEE, Thessaloniki, Greece.

Farzampour, A. and Eatherton, M. R. (2018b). "Parametric study on butterfly-shaped shear links with various geometries." Proc., 11th National Conference on Earthquake Engineering, 11NCEE, Los Angeles, USA.

Farzampour, A. and Eatherton, M. R. (2019). "Yielding and lateral torsional buckling limit states for butterfly-shaped shear links." Engineering Structures, 180, pp. 442-451.

Farzampour, A., Eatherton, M. R. (2019). "Parametric Computational Study on Butterfly-Shaped Hysteretic Dampers." Frontiers of Structural and Civil Engineering, Springer, 13(5), pp. 1214-1226. 
Farzampour, A., Mansouri, I. and Dehghani, H. (2019). "Incremental dynamic analysis for estimating seismic performance of multi-story buildings with butterfly-shaped structural dampers." Buildings, 9(4), pp. 78.

Farzampour, A. (2019). "Evaluating shear links for use in seismic structural fuses", (Doctoral dissertation, Virginia Tech).

Farzampour, A., Mansouri, I., Lee, C. H., Sim, H. B., \& Hu, J. W. (2018). “Analysis and design recommendations for corrugated steel plate shear walls with a reduced beam section", Thin-Walled Structures, 132, 658-666.

Farzampour, A., and Yekrangnia, M. (2014). “ON THE BEHAVIOROF CORRUGATED STEEL SHEAR WALLS WITH AND WTHOUT OPENINGS", In Second European conference on earthquake engineering and seismology.

Gandomi, A. H. and Alavi, A. H. (2012). "A new multi-gene genetic programming approach to nonlinear system modeling. Part I: Materials and structural engineering problems." Neural Computing and Applications, 21(1), pp. 171-187.

Gandomi, A. H., Alavi, A. H., Asghari, A., Niroomand, H. and Nazar, A. M. (2014a). "An innovative approach for modeling of hysteretic energy demand in steel moment resisting frames." Neural Computing and Applications, 24(6), pp. 1285-1291.

Gandomi, A. H., Alavi, A. H., Kazemi, S. and Gandomi, M. (2014b). "Formulation of shear strength of slender RC beams using gene expression programming, part I: Without shear reinforcement." Automation in Construction, 42, pp. 112-121.

Güllü, H. (2012). "Prediction of peak ground acceleration by genetic expression programming and regression: A comparison using likelihood-based measure." Engineering Geology, 141142, pp. 92-113. 
ICC, editor, SEAOC Structural/Seismic Design Manual 2009 IBC Vol 4: Building Design Examples for Steel-Framed Buildings, SEAOC, 2012.

Kim, Y. J., Ahn, T. S., Bae, J. H. and Oh, S. H. (2016). "Experimental study of using cantilever type steel plates for passive energy dissipation." International Journal of Steel Structures, 16(3), pp. 959-974.

Lim, W. Y. and Kim, S. (2017). "Experimental assessment of seismic vulnerability of precast concrete beam-to-beam connections with steel slit damper." International Journal of Steel Structures, 17(3), pp. 1249-1260.

Luth, G., Krawinkler, H. and McDonald, B. (2008). "USC School of Cinema: An example of reparable performance based design." Proc., 77th Annual Structural Engineers Association of California (SEAOC) Convention, Structural Engineers Association of Southern California, Fulllerton, CA.

Mahdavi Jafari, M. and Khayati, G. R. (2018). "Prediction of hydroxyapatite crystallite size prepared by sol-gel route: gene expression programming approach." Journal of Sol-Gel Science and Technology, 86(1), pp. 112-125.

Mansosuri, I. and Farzampour, A. (2018). "Buckling assessment of imperfect cylindrical shells under axial loading using a GEP technique." E-GFOS, pp. 89-100.

Mansouri, I., Chacón, R. and Hu, J. W. (2017a). "Improved predictive model to the cross-sectional resistance of CFT." Journal of Mechanical Science and Technology, 31(8), pp. 3887-3895.

Mansouri, I., Hu, J. W. and Kişi, O. (2016a). "Novel predictive model of the debonding strength for masonry members retrofitted with FRP." Applied Sciences (Switzerland), 6(11). 
Mansouri, I., Kisi, O., Sadeghian, P., Lee, C. H. and Hu, J. W. (2017b). "Prediction of ultimate strain and strength of FRP-confined concrete cylinders using soft computing methods." Applied Sciences (Switzerland), 7(8).

Mansouri, I., Safa, M., Ibrahim, Z., Kisi, O., Tahir, M. M., Baharom, S. and Azimi, M. (2016b). "Strength prediction of rotary brace damper using MLR and MARS." Structural Engineering and Mechanics, 60(3), pp. 471-488.

Mirzai, N. M., Attarnejad, R. and Hu, J. W. (2018). "Enhancing the seismic performance of EBFs with vertical shear link using a new self-centering damper." Ingegneria Sismica, 35(4), pp. $57-76$.

Mirzai, N. M., Attarnejad, R. and Hu, J. W. (2019). "Analysis investigation of the behavior of new smart recentering shear damper under cyclic loading." Journal of Intelligent Material Systems and Structures, in Press.

Mirzai, N. M. and Hu, J. W. (2019). "Pilot study for investigating the inelastic response of a new axial smart damper combined with friction devices." Steel and Composite Structures, 32(3), pp. 373-388.

Nie, L., Gao, L., Li, P. and Li, X. (2013). "A GEP-based reactive scheduling policies constructing approach for dynamic flexible job shop scheduling problem with job release dates." Journal of Intelligent Manufacturing, 24(4), pp. 763-774.

Onen, F. (2014). "Prediction of Scour at a Side-Weir with GEP, ANN and Regression Models." Arabian Journal for Science and Engineering, 39(8), pp. 6031-6041.

Sadeghian, P. and Fam, A. (2015). "Improved design-oriented confinement models for FRPwrapped concrete cylinders based on statistical analyses." Engineering Structures, 87, pp. 162-182. 
Saffari, H., Hedayat, A. A. and Nejad, M. P. (2013). "Post-Northridge connections with slit dampers to enhance strength and ductility." Journal of Constructional Steel Research, 80, pp. 138-152.

Shin, M., Kim, S.-P., Halterman, A. and Aschheim, M. (2017). "Seismic toughness and failure mechanisms of reduced web-section beams: Phase 1 tests." Engineering Structures, 141, pp. 198-216.

Smith, G. N. (1986). Probability and Statistics in Civil Engineering. New York: Collins Professional and Technical Books.

Tsai, K.-C., Chen, H.-W., Hong, C.-P. and Su, Y.-F. (1993). "Design of steel triangular plate energy absorbers for seismic-resistant construction." Earthquake Spectra, 9(3), pp. 505528.

Zakaria, N. A., Azamathulla, H. M., Chang, C. K. and Ghani, A. A. (2010). "Gene expression programming for total bed material load estimation-a case study." Science of the Total Environment, 408(21), pp. 5078-5085.

Zeynali, K., Saeed Monir, H., Mirzai, N. M. and Hu, J. W. (2018). "Experimental and numerical investigation of lead-rubber dampers in chevron concentrically braced frames." Archives of Civil and Mechanical Engineering, 18(1), pp. 162-178. 